\title{
CHEMICAL CONSTITUENTS AND MOLLUSCICIDAL ACTIVITY OF IRIS PSEUDACORUS L. CULTIVATED IN EGYPT
}

\author{
H. G. Sary $^{1}$, N A. Ayoub ${ }^{1}$, A. B. Singab ${ }^{1 *}$, A. H. Ahmed ${ }^{2}$, M. M. Al-Azizi ${ }^{1}$ \\ ${ }^{1}$ Department of Pharmacognosy, Ain Shams University, Faculty of Pharmacy, Abbassia, \\ Cairo, Egypt \\ ${ }^{2}$ National Hepatology and Tropical Medicine Research Institute, General Organization of \\ Teaching Hospitals and Institutes
}

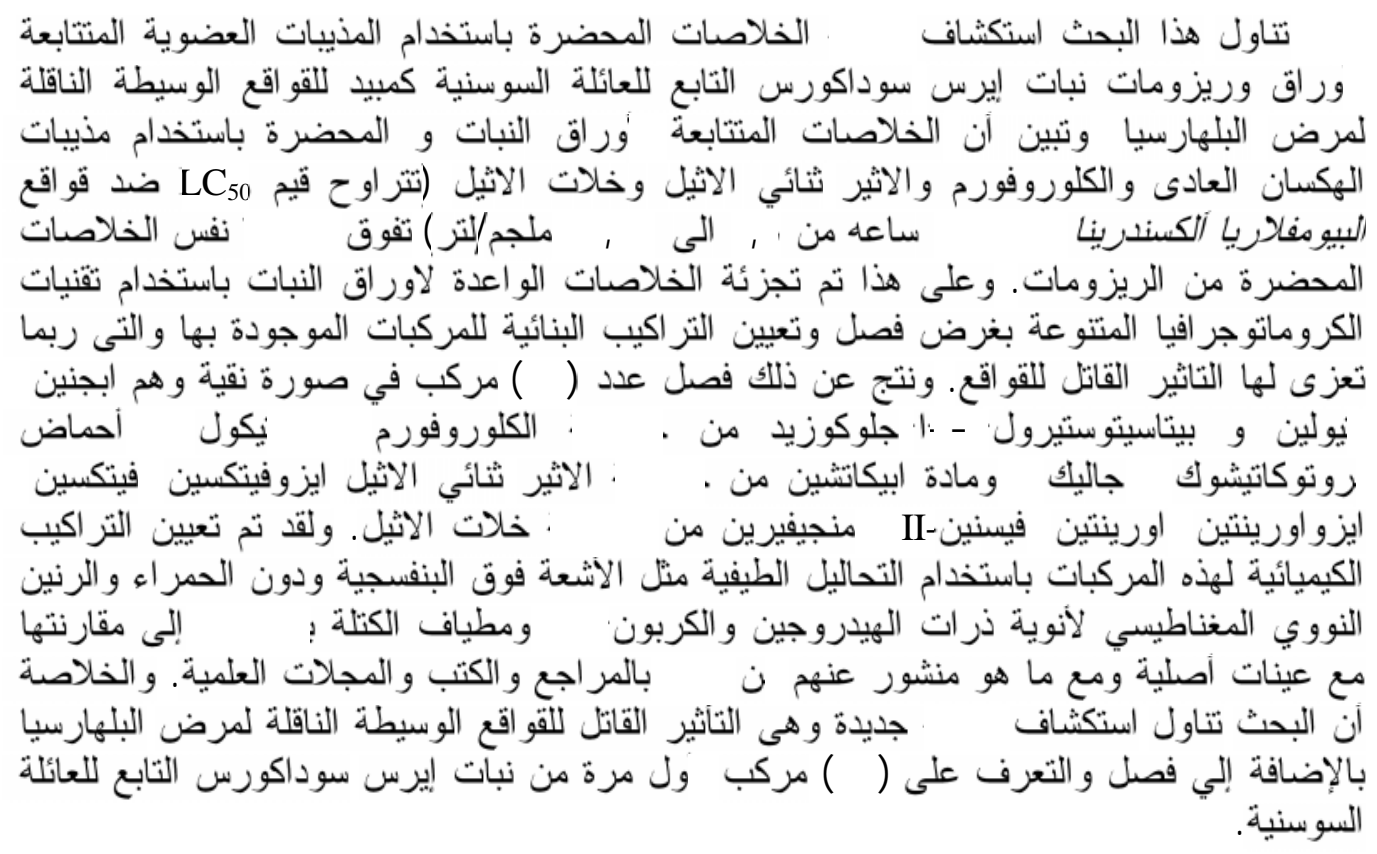

The molluscicidal activity of leaves and rhizomes extracts of Iris pseudacorus L. family Iridiaceae against Biomphalaria alexandrina snails were evaluated and proved activity. The successive extracts of leaves viz; n-hexane, chloroform, diethyl ether and ethyl acetate ( $L_{50}$ values ranged from $0.8 \sim 14.65 \mathrm{mg} / \mathrm{L}$ ) were found to be more potent than those of rhizomes. Bioactivity guided fractionation of leaves extracts resulted in the isolation of (13) compounds. The structural determination of the isolated compounds was established upon the study of their physicochemical and spectral data including $U V, I R,{ }^{1} \mathrm{H},{ }^{13} \mathrm{C}-\mathrm{NMR}$ and $M S$ as well as comparison with the data reported in literature. These compounds were identified as: apigenin (1), luteolin (2), $\beta$-sitosterol-3-O-glucoside (3), catechol (4), protocatechuic acid (5), gallic acid (6), (-)-epicatechin (7), iso-vitexin (8), vitexin (9), iso-orientin (10), orientin (11), vicenin II (12) and mangiferin (13). Reviewing the available literature, this is the first report regarding the determination of molluscicidal activity as well as isolation and identification of these compounds from Iris pseudacorus $L$.

\section{INTRODUCTION}

Snail control is considered as one of the most rapid and effective mean of reducing transmission of schistosomiasis. ${ }^{1}$ The potential use of plant extracts for biological control of the intermediate hosts of human schistosomiasis and other snail-transmitted parasitic infections has recently received considerable attention. ${ }^{2}$ Iris is the largest genus of family Iridiaceae, includes about 300 species; ${ }^{3}$ Iris pseudacorus $\mathrm{L}$ is a semi-aquatic

Received in 3/4/2004 \& Accepted in 8/5/2004

*To whom correspondence should be addressed, E-mail: nasersingab@hotmail.com 
plant could be easily cultivated on the river, by the side of canals and ponds to act as an effective means of reducing transmission of schistosomiasis by killing their intermediate host. The presence of several isoflavones, $C$ glycosyl xanthones, iridals, quinones, rotenoids and coumaronochromones in Iris plants is well documented. ${ }^{4-10}$ Though, iridal glycosides were isolated for the first time from Iris spuria (Zeal) cultivated in Egypt. ${ }^{11}$

As a continuation to our work on Iris plants, ${ }^{11}$ aiming to explore their chemical constituents as well confirming molluscicidal activity, Iris pseudacorus was chosen as the subject of this publication. The bioactivityguided fractionation was followed and the results showed that the active successive extracts of leaves were more potent than those of rhizomes. Therefore, the most potent extracts were subjected to phytochemical study, which resulted in isolation and identification of (13) compounds for the first time from the entitled plant.

\section{EXPERIMENTAL}

General: Mp: uncorr. ${ }^{1} \mathrm{H}$ and ${ }^{13} \mathrm{C}-\mathrm{NMR}$, were carried out on Bruker AMX 500 spectrometer (Germany). ESI/MS: Micromass Quattro-LC triple quadrupole mass spectrometer equipped with a "Z-Spray" electrospray ion source. All UV spectra were measured using standard procedures for flavonoids, ${ }^{12}$ using UV-1601 PC spectrophotometer, Shimadzu, Japan. CC: Silica gel 60 (70-230 mesh, E. Merck), LH-20 (25-100 m) Pharmacia Inc., Sweden. Paper Chromatography, Whatman paper No. 1 and No. 3 (Whatman Ltd. Maidstone, Kent, England). Precoated silica gel $60 \mathrm{~F}_{254}$ plates (E. Merck) were used for TLC.

\section{Materials and methods \\ Plant material}

The fresh leaves and rhizomes of Iris pseudacorus L. family Iridiaceae were collected during the flowering stage (April2001) from Faculty of Agriculture at Moshtohor, Zagazig University (Banha Branch) and identified by Dr. Abd El Salaam Mohamed Al-Nowiahi, Professor of Taxonomy, Faculty of Science, Ain Shams University, Abbassia, Cairo, Egypt. Voucher specimen of the authenticated plant was deposited at Department of Pharmacognosy, Faculty of
Pharmacy, Ain Shams University, Abbassia, Cairo, Egypt.

\section{Molluscicidal activity}

The fresh leaves and rhizomes of Iris pseudacorus $(1 \mathrm{~kg})$ were successively extracted with n-hexane, chloroform, diethyl ether, ethyl acetate and methanol respectively. Each extract was concentrated under reduced pressure at temperature not exceeding $45^{\circ}$. The procedure applied for screening tests on adult snails was based on the provisional testing technique recommended by the WHO (1965). ${ }^{13}$ Biomphalaria alexandrina snails, with an average diameter of $9 \mathrm{~mm}$, were used for the bioassay. Snails were collected from irrigation canals, located in Giza Governorate, kept under laboratory condition for a period of at least 3 weeks before being used in toxicity tests. Stock solutions were prepared by dissolving $1 \mathrm{~g}$ of each crude extract in the minimal amounts of $\mathrm{EtOH}$, then made up to $1000 \mathrm{mg} / \mathrm{L}$ concentration by adding suitable volumes of distilled water. At least six concentrations, with five replicates each, were tested for each type of plant extract. Groups of 10 adult snails were immersed in $500 \mathrm{ml}$ of each concentration. Similar numbers of control snails were maintained in normal dechlorinated water containing ethanol concentration as in treatment proved effective in each test. Exposure time of 24 hours was used with each concentration for determining the $\mathrm{LC}_{50}$ and $\mathrm{LC}_{90}$. Snails were allowed to recover for 48 hours and considered to be dead when they were retracted in their shells and discolored. The method described by Litchfield and Wilcoxon (1949) ${ }^{14}$ was used for the statistical analysis of the mortality data. The results are presented in Table (1 and 2).

\section{Extraction}

The fresh leaves of Iris pseudacorus L (9 $\mathrm{kg}$ ) was successively extracted with n-hexane, chloroform, diethyl ether, ethyl acetate and methanol respectively. Each extract was separately concentrated under reduced pressure at temperature not exceeding $45^{\circ}$ to give $25 \mathrm{~g}$, $18 \mathrm{~g}, 21 \mathrm{~g}, 17$ and $245 \mathrm{~g}$ respectively. The molluscicidal active leaves extracts viz; chloroform, diethyl ether and ethyl acetate extracts were subjected to chromatographic fractionation using different stationary phases and mobile phases. 
Table 1: Molluscicidal activities of alcohol extract and different successive extracts of Iris pseudacorus leaves against B. alexandrina after 24 hours exposure period.

\begin{tabular}{||l|c|c|c|}
\hline \multirow{2}{*}{\multicolumn{1}{c|}{$\begin{array}{c}\text { Type of } \\
\text { Extract }\end{array}$}} & \multicolumn{2}{|c|}{ Activity (mg/liter) } & \multirow{2}{*}{ Slope } \\
\cline { 2 - 3 } & $\mathrm{LC}_{50}$ and $(95 \% \mathrm{cl})$ & $\mathrm{LC}_{90}$ & \\
\hline Total alcohol & $1.54(1.43-1.66)$ & 2.51 & 1.46 \\
\hline n Hexane & $6.51(5.9-7.16)$ & 12.17 & 1.55 \\
\hline Chloroform & $0.8(0.66-0.94)$ & 2.1 & 2.07 \\
\hline Ether & $1.18(1.08-1.28)$ & 1.85 & 1.46 \\
\hline Ethyl acetate & $14.65(13.3-16.14)$ & 25.07 & 1.48 \\
\hline Ethyl alcohol & $29.83(25.64-35.06)$ & 70.53 & 1.94 \\
\hline Methyl alcohol & $247.07(234.12-260.59)$ & 332.12 & 1.27 \\
\hline
\end{tabular}

Total alcohol was prepared by extraction of ( $200 \mathrm{~g})$ fresh leaves by $70 \%$ ethanol for preliminary molluscicidal test.

n-hexane extract proved to contain essential oils as major constituents and the chemical composition of the oil content is going to be the subject of another publication.

Table 2: Molluscicidal activities of alcohol extract and different successive extracts of the Iris pseudacorus rhizomes against $B$. alexandrina after 24 hours exposure period.

\begin{tabular}{|l|c|c|c|}
\hline \multirow{2}{*}{\multicolumn{1}{c|}{$\begin{array}{c}\text { Type of } \\
\text { Extract }\end{array}$}} & \multicolumn{2}{|c|}{ Activity $(\mathrm{mg} /$ liter $)$} & \multirow{2}{*}{ Slope } \\
\cline { 2 - 3 } & $\mathrm{LC}_{50}$ and $(95 \% \mathrm{cl})$ & LC $_{90}$ & \\
\hline Total alcohol & $2.14(1.93-2.38)$ & 3.8 & 1.58 \\
\hline n Hexane & $11.22(10.29-12.23)$ & 18.49 & 1.48 \\
\hline Chloroform & $16.03(14.57-17.63)$ & 29.51 & 1.6 \\
\hline Ether & $1.05(0.95-1.17)$ & 1.89 & 1.59 \\
\hline Ethyl acetate & $22.91(21.02-24.97)$ & 38.02 & 1.49 \\
\hline Ethyl alcohol & $257.04(227.47-290.46)$ & 501.19 & 1.69 \\
\hline Methyl alcohol & \multicolumn{2}{|c|}{ Inactive at 500 ppm } \\
\hline
\end{tabular}

* Total alcohol was prepared by extraction of ( $200 \mathrm{~g})$ fresh rhizomes by $70 \%$ ethanol for preliminary molluscicidal test.

\section{Isolation and identification \\ Compounds 1 3}

The molluscicidal active chloroformic leaves extract $(9 \mathrm{~g})$ was subjected to $\mathrm{CC}$ on silica gel G (200 g), eluted initially with: chloroform then chloroform: methanol (99:1) followed by gradual increasing of methanol to give 14 fractions.

\section{Compound 1}

Fraction no. 9 eluted with $\mathrm{CHCl}_{3}: \mathrm{MeOH}$ (96:4), showed a major spot, which appeared as deep purple under UV light on $\mathrm{PC}$ with $\mathrm{HR}_{\mathrm{f}} 89$ (BAW), 83 (Forestal) and 88 (PhOH). Crystallization from hot methanol afforded yellow powder $(7 \mathrm{mg}), \mathrm{UV} \lambda_{\max }^{\mathrm{MeOH}}(\mathrm{nm}) 355$, 266; $\mathrm{NaOMe} 390,319,275 ; \mathrm{AlCl}_{3} 384,348$,
305, 272; $\quad \mathrm{AlCl}_{3} / \mathrm{HCl} 381,340,301, \quad 272$; $\mathrm{NaOAc} 373,300,272$ and $\mathrm{NaOAc} / \mathrm{H}_{3} \mathrm{BO}_{3} 340$, $300 \mathrm{sh}, 272 .{ }^{1} \mathrm{H}-\mathrm{NMR} \delta(\mathrm{ppm}) 6.18(\mathrm{~d}, J=2.5$ Hz, H-6), 6.47 (d, J=2.5 Hz, H-8), 6.77 (s, H3), $6.92\left(\mathrm{~d}, J=8 \mathrm{~Hz}, \mathrm{H}-3{ }^{`}, \mathrm{H}-5^{`}\right), 7.93(\mathrm{~d}, J=8$ $\left.\mathrm{Hz}, \mathrm{H}-2^{\prime}, \mathrm{H}-6^{\prime}\right)$. Comparing the above data with those reported for apigenin, ${ }^{12}$ proved unequivocally that compound $\mathbf{1}$ is apigenin.

\section{Compound 2}

Fraction no. 11 eluted with $\mathrm{CHCl}_{3}: \mathrm{MeOH}$ (90:10), gave a major dark purple spot on PC under UV light with $\mathrm{HR}_{\mathrm{f}} 78$ (BAW), and 66 $(\mathrm{PhOH})$ under UV light. On crystallization from hot methanol it gave a yellow amorphous powder $(10 \mathrm{mg})$ of compound 2 . UV $\lambda_{\max }^{\mathrm{MeOH}}$ (nm) 350, 267; NaOMe 400, 330 sh, 267; $\mathrm{AlCl}_{3}$ 
422, 348, 330, 300, 274; $\mathrm{AlCl}_{3} / \mathrm{HCl} 385,355$, 294 sh, 276; NaOAc 384, 328 sh, 269; $\mathrm{NaOAc} / \mathrm{H}_{3} \mathrm{BO}_{3} 430$ sh, 370, 301 sh, 259. ${ }^{1} \mathrm{H}-$ NMR $\delta$ (ppm) 6.19 (d, J=2.5 Hz, H-6), 6.46 (d, $J=2.5 \mathrm{~Hz}, \mathrm{H}-8), 6.85$ (s, H-3), 7.5 (d, $J=2.5$ Hz, H-2`), 6.89 (d, $J=8 \mathrm{~Hz}, \mathrm{H}-5{ }^{`}$ ), 7.45 (dd, $J=$ $2.5 \mathrm{~Hz}$ and $J=8 \mathrm{~Hz}, \mathrm{H}-6)^{\prime}$ ). These data were in accordance with those reported for luteolin. ${ }^{12}$ Co-chromatography with authentic luteolin confirmed that compound $\mathbf{2}$ is luteolin.

\section{Compound 3}

Fraction no. 12 eluted with $\mathrm{CHCl}_{3}: \mathrm{MeOH}$ (85:15), afforded after crystallization from hot methanol a white needle crystals $(200 \mathrm{mg}), \mathrm{mp}$ 280-283 ${ }^{\circ}$. It gave one spot on TLC using different solvent systems. IR ( $\mathrm{KBr}$ disc) $v \mathrm{~cm}^{-1}$ $3360(\mathrm{OH}), 1640 \mathrm{~cm}^{-1}(\mathrm{C}=\mathrm{C}), 1160,1070$ and 1020 (-C-O). The identity of this compound, as $\beta$-sitosterol-3-O-glucoside based upon acid hydrolysis followed by chromatographic analysis as well as comparing of its $R_{\mathrm{f}}$ values using different solvent systems, m.m.p, m.p and IR spectral data with those of authentic of $\beta$ sitosterol-3-O-glucoside.

\section{Compounds 4 7}

Part of the residue of diethyl ether extract of leaves $(5 \mathrm{~g})$ was subjected to 2D-PC using $15 \%$ acetic acid and BAW (4:1:5) respectively. The chromatogram revealed the presence of four major spots, phenolic in nature being positive with $\mathrm{FeCl}_{3}$. Compounds (4-7) were isolated on preparative PC, using $15 \%$ acetic acid as developing system and each compound was purified on a sephadex LH-20 CC using $\mathrm{MeOH}$ as mobile phase.

\section{Compound 4}

Obtained as an amorphous white powder (6 mg), it appeared as a blue spot on PC under short UV light, with $\mathrm{HR}_{\mathrm{f}} 80$ and 85 values using $15 \%$ acetic acid and BAW (4:1:5) as solvent system respectively. UV $\lambda_{\max }^{\mathrm{MeOH}}(\mathrm{nm})$ 279. ${ }^{1} \mathrm{H}-\mathrm{NMR}$ ( $\delta \mathrm{ppm}$, DMSO- $d_{6}$, at room temperature) showed signal at $\delta 6.57$ to 6.70 (m, H-3, H-6, H-4 and H-5) forming AB spin system, such spin system produce unresolved multiplet in the aromatic region between $\delta 6.57$ to $6.70 \mathrm{ppm}$. Comparing these values with reported data ${ }^{15,16}$ concerning catechol proved its identity as catechol.

\section{Compound 5}

Obtained as off-white amorphous powder (5 mg); it appeared as an intense blue spot on PC under short UV light $\mathrm{HR}_{\mathrm{f}} 90$ and 94 values using $15 \%$ acetic acid and BAW (4:1:5) as solvent system respectively. It gave reddish color with aniline/xylose reagent, specific for carboxylic acid. ${ }^{17} \mathrm{UV} \lambda_{\max }^{\mathrm{MeOH}}$ (nm) 293.40 and 259.40; ESI/MS: $\mathrm{M}_{\mathrm{r}}$ 154, ESI/MS: (negative ion): $\mathrm{m} / \mathrm{z}[\mathrm{M}-\mathrm{H}] 153$ indicating $\mathrm{C}_{7} \mathrm{H}_{6} \mathrm{O}_{4} \cdot{ }^{1} \mathrm{H}-$ NMR ( $\delta$ ppm DMSO- $d_{6}$, at room temperature) 7.35 (d, $J=2.5 \mathrm{~Hz}, \mathrm{H}-2), 6.80$ (d, $J=7 \mathrm{~Hz}, \mathrm{H}-5)$ and $7.28(\mathrm{dd}, J=7 \mathrm{~Hz} \& J=2.5 \mathrm{~Hz}, \mathrm{H}-6) .{ }^{13} \mathrm{C}-$ NMR $\delta(\mathrm{ppm}) 122.52$ (C-1), 116.84 (C-2), 145.0 (C-3), 150.0 (C-4), 115.28 (C-5), 121.84 (C-6), $167.96(\mathrm{COOH})$. The above data were in complete accordance with those published regarding the protocatechuic acid. ${ }^{18}$ Consequently compound $\mathbf{5}$ is protocatechuic acid.

\section{Compound 6}

Obtained as off-white amorphous powder (7 mg), appeared as an intense blue spot on PC under short UV light with $\mathrm{HR}_{\mathrm{f}} 53\left(\mathrm{H}_{2} \mathrm{O}\right)$ and 78 (BAW). It gave reddish colour with aniline/xylose reagent, specific for carboxylic acid. ${ }^{17} \mathrm{UV} \lambda_{\max }^{\mathrm{MeOH}}$ (nm) 215, 272; ESI/MS: $\mathrm{M}_{\mathrm{r}}$ 170, ESI/MS: negative ion: m/z [M-H] $]^{-}: 168.96$ consisting with $\mathrm{C}_{7} \mathrm{H}_{6} \mathrm{O}_{5}$. ${ }^{1} \mathrm{H}-\mathrm{NMR}(\delta \mathrm{ppm}$ DMSO- $d_{6}$, at room temperature) 6.98 (s, H-2 \& H-6). ${ }^{13} \mathrm{C}-\mathrm{NMR} \delta$ (ppm) 120.6 (C-1), 108.8 (C2 \& C-6), 145.5 (C-3 \& C-5), 138.1 (C-4), 167.7 (C-7). Comparsion of the above data with those published for gallic acid, ${ }^{19}$ proved the identity of compound $\mathbf{6}$ as gallic acid.

\section{Compound 7}

Obtained as off-white amorphous powder (6 mg), it appeared as a blue spot on a $2 \mathrm{D}$ cellulose plate under short UV light and turned reddish violet on spraying with vanillin/HCI reagent and subsequent heating of the plate for 2-3 minutes at $100^{\circ}$ (specific for condensed tannins). UV $\lambda_{\max }^{\mathrm{MeOH}}(\mathrm{nm}) 269 .{ }^{1} \mathrm{H}-\mathrm{NMR}(\delta$ ppm DMSO- $d_{6}$, at room temperature) $4.85(\mathrm{~s}$, H-2), 4.22 (m, H-3), 2.86 (ax., dd, $J=16.4 \mathrm{~Hz}$ and $4.4 \mathrm{~Hz}, \mathrm{H}-4$ ), 2.74 (eq., dd, $J=16.4 \mathrm{~Hz}$ and $3.5 \mathrm{~Hz}, \mathrm{H}-4), 6.0$ (d, J=2.3 Hz, H-6), 5.92 (d, $J=2.3 \mathrm{~Hz}, \mathrm{H}-8), 7.02$ (d, $\left.J=1.9 \mathrm{~Hz}, \mathrm{H}-2{ }^{\prime}\right), 6.76$ $\left.(\mathrm{d}, J=8.0 \mathrm{~Hz}, \mathrm{H}-5)^{`}\right), 6.82(\mathrm{dd}, J=8.0 \mathrm{~Hz}$ and $1.9 \mathrm{~Hz}, \mathrm{H}-6) ;{ }^{13} \mathrm{C}-\mathrm{NMR} \delta$ (DMSO $d_{6}, \mathrm{ppm}$ ) 
79.1 (C-2), 66.8 (C-3), 82.5 (C-4), 157.3 (C-5), 96.1 (C-6), 157.2 (C-7), 95.6 (C-8), 156.8 (C9), 99.6 (C-10), 131.9 (C-1'), 115.5 (C-2'), 144.9 (C-3`), 145.1 (C-4`), 115.0 (C-5`), 119.2 (C-6). The data reported for (-)-Epicatechin were found to be in accordance with above data. ${ }^{20}$ So, compound 7 is deduced as (-)Epicatechin.

\section{Compounds 8 13}

Part of the ethyl acetate extract of the leaves $(6 \mathrm{~g})$ was fractionated over a sephadex LH-20 CC (250 g) and eluted with water followed by water: methanol mixture of decreasing polarity. The elution process was monitored by UV light, whereby six fractions (I-VI) were, individually, eluted, collected and dried in vасио at $45^{\circ}$. Five phenolic compounds were detected in fraction (II) and one in fraction (III) using 2D PC.

Fraction II (1 g) was chromatographed over sephadex LH-20 CC eluted with n-butanol saturated with water, and the collected fractions were monitored by 2DPC. Five flavonoid glycosides were obtained. These compounds resist acid hydrolysis and undergone Wessely-Moser rearrangement indicating the $C$-glycoside in nature. ${ }^{12}$

\section{Compound 8}

Obtained as pale yellow amorphous powder (9mg), it appeared as a dark purple spot on $\mathrm{PC}$ under UV light with $\mathrm{HR}_{\mathrm{f}} 69$ (BAW), 55 (\%15 HOAc) and $41\left(\mathrm{H}_{2} \mathrm{O}\right)$. UV $\lambda_{\max }^{\mathrm{MeOH}}(\mathrm{nm})$ 332, 272; NaOMe 399,333 sh, 281; $\mathrm{AlCl}_{3} 385$, 340, 305, 278; $\mathrm{AlCl}_{3} / \mathrm{HCl} 391,305$ sh, 281 sh, 270; $\mathrm{NaOAc} 391,305$ sh, 281; $\mathrm{NaOAc} / \mathrm{H}_{3} \mathrm{BO}_{3}$ $400 \mathrm{sh}, 335,278 .{ }^{1} \mathrm{H}-\mathrm{NMR}$ ( $\delta$ ppm DMSO- $d_{6}$, at room temperature) $7.93(2 \mathrm{H}, \mathrm{d}, J=8 \mathrm{~Hz}, \mathrm{H}-$ 2`, H-6`), 6.92 (2H, d, J= $\left.8 \mathrm{~Hz}, \mathrm{H}-3 `, \mathrm{H}-5{ }^{`}\right)$, $6.77(1 \mathrm{H}, \mathrm{s}, \mathrm{H}-3), 6.47(1 \mathrm{H}, \mathrm{s}, \mathrm{H}-8), 4.7(1 \mathrm{H}, \mathrm{d}$, $J=8 \mathrm{~Hz}, \mathrm{H}-1$ glucose), 3.0-3.9 (m, sugar protons). Acid hydrolysis of 8 resulted in two flavonoidal spots as appeared on PC indicating, according to Wessely-Moser rearrangement, the $C$-glycoside nature of 8 . In addition, ${ }^{1} \mathrm{H}$ NMR $\delta(\mathrm{ppm})$ indicated the absence of signal due to H-6 and appearance of singlet at $\delta 6.47$ (H-8). The identity of compound $\mathbf{8}$ as isovitexin was achieved by comparison of its $R_{f}$ values with those of authentic (iso-vitexin) apigenin- $6-C-\beta-\mathrm{D}$-glucopyarnoside as well as comparison of its spectral data with those reported in literature. ${ }^{21}$

\section{Compound 9}

Obtained as pale yellow amorphous material $(8 \mathrm{mg})$ and appeared as a dark purple spot on PC under UV light, $\mathrm{HR}_{\mathrm{f}} 52$ (BAW), 29 (15\% HOAc) and $35\left(\mathrm{H}_{2} \mathrm{O}\right)$. UV $\lambda_{\max }^{\mathrm{MeOH}}(\mathrm{nm})$ 334, 272; NaOMe 391, 332 sh, 281; $\mathrm{AlCl}_{3} 385$, 340, 305, 278; $\mathrm{AlCl}_{3} / \mathrm{HCl} 391,305 \mathrm{sh}, 281 \mathrm{sh}$, 276; $\mathrm{NaOAc} 391,305 \mathrm{sh}, 281 ; \mathrm{NaOAc} / \mathrm{H}_{3} \mathrm{BO}_{3}$ $400 \mathrm{sh}, 339,278 .{ }^{1} \mathrm{H}-\mathrm{NMR}$ ( $\delta$ ppm, DMSO- $d_{6}$, at room temperature $) 7.93(2 \mathrm{H}, \mathrm{d}, J=8 \mathrm{~Hz}, \mathrm{H}-$ 2`,H-6'), 6.92 (2H, d, J= 8 Hz, H-3`, H-5`), $6.77(1 \mathrm{H}, \mathrm{s}, \mathrm{H}-3), 6.21(1 \mathrm{H}, \mathrm{s}, \mathrm{H}-6), 4.63(1 \mathrm{H}$, $\mathrm{d}, J=8 \mathrm{~Hz}, \mathrm{H}-1$ glucose), 3.1-3.9 (m, sugar protons). Upon acid hydrolysis compound 9 was converted to 2 flavonoidal spots on PC indicating, according to Wessely-Moser rearrangement the $C$-glycoside nature of this compound. In addition, ${ }^{1} \mathrm{H}-\mathrm{NMR} \quad \delta(\mathrm{ppm})$ indicated the absence of signal due to $\mathrm{H}-8$ and appearance of singlet at $\delta 6.21(\mathrm{H}-6)$. The UV and NMR spectral data were in complete accordance with those reported for vitexin. ${ }^{22}$ The identity of this compound was further confirmed by co-chromatography with authentic vitexin. Thus, compound 9 was unequivocally identified as (vitexin), apigenin8- $C$ - $\beta$-D-glucopyarnoside.

\section{Compound 10}

Obtained as yellow amorphous material $(11 \mathrm{mg})$ and appeared as a dark purple spot on PC under UV light with $\mathrm{HR}_{\mathrm{f}} 44$ (BAW), 37 $(\% 15 \mathrm{HOAc})$ and $10\left(\mathrm{H}_{2} \mathrm{O}\right)$. UV $\lambda_{\max }^{\mathrm{MeOH}}(\mathrm{nm})$ 348, 269; NaOMe 403, 327, 278; $\mathrm{AlCl}_{3} 428$, 325, 278; $\mathrm{AlCl}_{3} / \mathrm{HCl} 385,350,298$ sh, 278; $\mathrm{NaOAc} 385,320,278, \mathrm{NaOAc} / \mathrm{H}_{3} \mathrm{BO}_{3} 430 \mathrm{sh}$, 375,$269 ;{ }^{1} \mathrm{H}-\mathrm{NMR} \delta$ (DMSO $\left.d_{6}, \mathrm{ppm}\right) 7.5(\mathrm{~d}$, $\left.J=2.5 \mathrm{~Hz}, \mathrm{H}-2^{\prime}\right), 6.93\left(\mathrm{~d}, J=8.5 \mathrm{~Hz}, \mathrm{H}-5^{\prime}\right)$, $7.45\left(\mathrm{dd}, J=2.5 \mathrm{~Hz}\right.$ and $\left.8.5 \mathrm{~Hz}, \mathrm{H}-6{ }^{\circ}\right), 6.50(\mathrm{~s}$, $\mathrm{H}-3), 6.45$ (s, H-8), 4.6 (d, J= $10 \mathrm{~Hz}, \mathrm{H}-1$ glucose), 3.0-4.2 (m, sugar protons). The identity of compound $\mathbf{1 0}$ was confirmed as isoorientin from interpretation of its UV and NMR spectral data and comparison with those reported on iso-orientin ${ }^{12}$ as well as cochromatography with authentic (iso-orientin) luteolin-6- $C$ - $\beta$-D-glucopyarnoside. 


\section{Compound 11}

Obtained as yellow amorphous material ( 8 $\mathrm{mg}$ ) and appeared as a dark purple spot on PC under UV light, $\mathrm{HR}_{\mathrm{f}} 32$ (BAW), 17 (15\% HOAc) and $6\left(\mathrm{H}_{2} \mathrm{O}\right)$. UV $\lambda_{\max }^{\mathrm{MeOH}}(\mathrm{nm}) 348,269$. Other UV shifting reagents $\mathrm{NaOMe} 391,332$ sh, 281; $\mathrm{AlCl}_{3} 385,340,305,278 ; \mathrm{AlCl}_{3} / \mathrm{HCl}$ 391, 305 sh, 281 sh, 276; NaOAc 391, 305 sh, 281; $\mathrm{NaOAc} / \mathrm{H}_{3} \mathrm{BO}_{3} 400$ sh, 339, 278 indicated the presence of free ortho-dihydroxy group at 3,4 and a free hydroxyl group at 5-position. Acid hydrolysis resulted in the absence of the sugar and the appearance of two flavonoidal spots on PC (Wessely-Moser interconversion) indicating the $\mathrm{C}$-glycoside nature of 11 . All of the above data pointed to an orientin. ${ }^{12}{ }^{1} \mathrm{H}$ NMR $\delta\left(\right.$ DMSO $\left.d_{6}, \mathrm{ppm}\right) 7.5(\mathrm{~d}, J=2.5 \mathrm{~Hz}, \mathrm{H}-$ 2), 6.93 (d, $J=8.5 \mathrm{~Hz}, \mathrm{H}-5$ ), 7.45 (dd, $J=2.5$ $\mathrm{Hz}$ and $8.5 \mathrm{~Hz}, \mathrm{H}-6$ ) , 6.45 (s, H-3), 6.18 (s, H6), 4.7 (d, $J=10 \mathrm{~Hz}, \mathrm{H}-1$ glucose), 3.2-3.9 (m, sugar protons). The ${ }^{1} \mathrm{H}-\mathrm{NMR}$ data indicated the absence of signal due to proton at C-8 and the presence of a singlet at $\delta 6.18(\mathrm{H}-6)$ suggested the structure of 11 to be, luteolin-6- $C$ - $\beta$-Dglucopyarnoside (orientin). The identity of 11 was based upon analysis of the above data as well as comparison with those published on orientin. $^{12}$

\section{Compound 12}

Obtained as yellow amorphous material $(20 \mathrm{mg})$ and appeared as a dark purple spot on $\mathrm{PC}$ under UV light with $\mathrm{HR}_{\mathrm{f}} 31$ (BAW) and 50 (15\% HOAc). UV $\lambda_{\max }^{\mathrm{MeOH}}(\mathrm{nm}) 272,297,330$; $\mathrm{AlCl}_{3} 282,305,317,350,398 ; \mathrm{AlCl}_{3} / \mathrm{HCl} 280$, 303, 343, 381; NaOMe, 283, 333, 398; NaOAc 282, 298 sh, 389; $\mathrm{NaOAc} / \mathrm{H}_{3} \mathrm{BO}_{3}$ 281, 299 sh, 355. (negative) ESI/MS: $M_{\mathrm{r}}$ 594, ESI/MS: negative ion: $\mathrm{m} / \mathrm{z}[\mathrm{M}-\mathrm{H}]^{-}: 593.4$ indicated $\mathrm{C}_{27} \mathrm{H}_{30} \mathrm{O}_{15} .{ }^{1} \mathrm{H}-\mathrm{NMR} \delta(\mathrm{ppm}) 7.8(2 \mathrm{H}, \mathrm{d}, J=9$ Hz, H-2', H-6'), 6.7 (2H, d, J=9 Hz, H-3', H5 ) $, 6.3(1 \mathrm{H}, \mathrm{s}, \mathrm{H}-3), 4.5(2 \mathrm{H}, \mathrm{m}, \mathrm{H}-1$ “ and $\mathrm{H}-$ $\left.1^{\prime \prime}\right)$, 3.8-2.9 (m, sugar protons); UV spectra indicated an apigenin-type with a free 7-OH [Mabry et al.]. The ${ }^{1} \mathrm{H}-\mathrm{NMR}$ confirmed the apigenin B-ring, exhibiting a singlet at $\delta 6.3$ for $\mathrm{H}-3$ and no signals for $\mathrm{H}-6$ or H-8. The presence of two $C$-linked glycosyl $\mathrm{H}-\underline{1 \mathrm{~s}}$ and also signals for two sugars were observed in the ${ }^{1} \mathrm{H}-\mathrm{NMR}$, indicating $\mathrm{C}$-linked sugars at 6 and 8 positions $^{22}$ respectively. ESI/MS (neg.) gave $\mathrm{m} / \mathrm{z}$ : $593[\mathrm{M}+1], 431$ [M-1-162] and 271 [M+1-162] indicating the di-glucosides of apigenin moiety. Co-chromatography against standards further confirmed the structure of compound $\mathbf{1 2}$ as vicenin-II $(6,8$ - $d i-C$ glucosylapigenin).

Fraction III was subjected to 2D PC, which revealed the presence of several minor spots plus a major one. Using descending PPC, the major spot was isolated using $15 \%$ acetic acid as solvent system and finally purified on a sephadex LH-20 column to give compound $\mathbf{1 3}$.

\section{Compound 13}

Obtained as yellow amorphous powder $(10 \mathrm{mg})$, which appeared as intense yellowish orange colour on PC under short UV light of $\mathrm{HR}_{\mathrm{f}}$-values 38 (BAW) and 24 (HOAc \%6). UV $\lambda_{\max }^{\mathrm{MeOH}}(\mathrm{nm}) 363,315,258,241$ suggesting a xanthones derivative. It exhibited in (negative) ESI/MS, molecular ion at m/z [M-H] $]^{-}: 421.20$ corresponding to $\mathrm{C}_{19} \mathrm{H}_{18} \mathrm{O}_{11}$. Compound $\mathbf{1 3}$ recovered unchanged after being refluxed with $(2 \mathrm{~N})$ methanolic $\mathrm{HCl}$ for seven hours suggested the C-glycosidic nature. ${ }^{1} \mathrm{H}-\mathrm{NMR} \delta(\mathrm{ppm}) 6.4$ (s, H-4), 6.78 (s, H-5), 7.35 (s, H-8). ${ }^{13} \mathrm{C}-\mathrm{NMR}$ $\delta$ (ppm) 161.79 (C-1), 107.42 (C-2), 163.83 (C3), 93.27 (C-4), 102.30 (C-5), 155.309 (C-6), 144.11 (C-7), 107.54 (C-8), 178.91 (C-9), 156.16 (C-4a), 151.11 (C-4b), 110.98 (C-8a), 101.21 (C-8b), 73.09 (C-1`), 70.65 (C-2`), 79.02 (C-3`), 70.20 (C-4`), 81.61 (C-5`), 61.50 (C-6). The results of the interpretation of the above data was found to be in complete accordance with those reported for mangiferin isolated before from the leaves of Iris germanica $\mathrm{L}^{23}$ 
<smiles>[R]c1cc(-c2cc(=O)c3c(O)c([R])c(O)c([R])c3o2)ccc1O</smiles>

$\begin{array}{llll} & \mathrm{R}_{1} & \mathrm{R}_{2} & \mathrm{R}_{3} \\ \text { (1) } & \mathrm{H} & \mathrm{H} & \mathrm{H} \\ \text { (2) } & \mathrm{OH} & \mathrm{H} & \mathrm{H} \\ \text { (8) } & \mathrm{H} & \mathrm{H} & \mathrm{Glc} \\ \mathbf{( 9 )} & \mathrm{H} & \mathrm{Glc} & \mathrm{H} \\ \mathbf{( 1 0 )} & \mathrm{OH} & \mathrm{H} & \mathrm{Glc} \\ \mathbf{( 1 1 )} & \mathrm{OH} & \mathrm{Glc} & \mathrm{H} \\ \mathbf{( 1 2 )} & \mathrm{H} & \mathrm{Glc} & \mathrm{Glc}\end{array}$<smiles>CC(C)CCCC(C)C1CCC2C3CC=C4CC(OC5CCCCC5)CCC4(C)C3CCC12C</smiles>

Compound (3)<smiles>Oc1ccccc1O</smiles>

Compound (4)<smiles>O=C(O)c1ccc(O)c(O)c1</smiles>

Compound (5)<smiles>O=C(O)c1cc(O)c(O)c(O)c1</smiles>

Compound (6)<smiles>Oc1cc(O)c2c(c1)O[C@H](c1ccc(O)c(O)c1)[C@H](O)C2</smiles>

Compound (7)<smiles>O=c1c2cc(O)c(O)cc2oc2c(O)c(Cl)c(O)cc12</smiles>

Compound (13) 


\section{RESULTS AND DISCUSSION}

In the present study, a semi aquatic plant Iris Pseudacorus L was screened for its molluscicidal activity. The validity of the test is maintained if it obeys the recommendation of WHO (an alcoholic or lipophilic solvent extract of the plant should have an $\mathrm{LC}_{90}$ against vector snails after $24 \mathrm{~h}$ at concentration equal to or less than $20 \mathrm{mg} / \mathrm{L}){ }^{24}$ Successive extracts of leaves and rhizomes were evaluated for their molluscicidal activity against Biomphalaria alexandrina adult snails. The $\mathrm{LC}_{50}, \mathrm{LC}_{90}$ and slope function values were determined and listed in (Tables 1 and 2) for different extracts of I. pseudacorus leaves and rhizomes respectively. The successive extracts of leaves were found to be more potent than those of the rhizomes. The n-hexane, chloroform and diethyl ether extracts of the leaves showed the highest molluscicidal activity $\left(\mathrm{LC}_{90}\right.$ less than $20 \mathrm{mg} / \mathrm{L}$ ), followed by ethyl acetate extract $\left(\mathrm{LC}_{90}=25.07 \mathrm{mg} / \mathrm{L}\right)$.

The potent chloroform extract of the leaves was fractionated on a column of silica gel resulted in the isolation and identification of 3 compounds. The identity of them based upon the comparison of their data with those published concerning apigenin, luteolin and $\beta$ sitosterol-3-O-glucoside. On the other hand, diethyl ether extract was found to be rich with simple phenolic compounds (intense blue color with $\mathrm{FeCl}_{3}$ ). Thus, preparative $\mathrm{PC}$ was used for isolation of these phenolic compounds followed by purification on LH-20 CC using methanol as mobile phase. Four compounds were isolated and identified as catechol, protocatechuic acid, gallic acid and (-) epicatechin based upon comparison of their data with those published in literature. To our knowledge, these compounds were isolated for the first time from the family Iridiaceae.

2D-PC analysis of ethyl acetate extract revealed the presence of six major phenolic spots, five of them gave the usual chemical reactions for flavonoids on PC using ultra violet light while the six one gave yellow orange spot intensified with ammonia vapors. Fractionation of ethyl acetate extract on Sephadex LH-20 CC yielded 6 fractions. Fraction 2 was the richest one with flavonoids. Repeated LH-20 CC and monitoring with PC resulted in the isolation of 5 flavonoid- C- glycosides for the first time from the entitled plant. These compounds were identified as isovitexin, vitexin, isoorientin, orientin, and vicenin-II by comparison of their spectral data with those reported in literature as well as cochromatography with authentic samples. Purification of fraction III by PPC followed by $\mathrm{CC}$ of LH-20 resulted in the isolation and identification of a xanthone- $C$-glucoside identified as mangiferin by comparison of its spectral data and chromatographic behaviors with those reported regarding mangiferin which reported here for the first time from this plant.

On the basis of the present study, $I$. pseudacorus could be used as potent molluscicidal being a semi aquatic ornamental plants which can be easily cultivated along the shores of the canals and drains to act as an effective means of reducing transmission of schistosomiasis by killing their intermediate host.

\section{REFERENCES}

1- S. F. Cullough MC, P. Gayral, J. Duncan and D. J.Christie, Bulletin of the World Health Organization, 58, 681-689 (1980).

2- World Health Organization Reports of the Scientific Working Group on Plant Molluscicides. Document TDR/SCHSWG/4/83.Geneva: WHO (1983).

3- W. C. Evans, Trease and Evans, Pharmacognosy, $14^{\text {th }}$ edition, 1996, p. 52.

4- M. Fujita and T. Inoue, Chem. Pharm. Bull., 30 (7) 2342 (1982).

5- N. A. El-Emary, Y. Kobayashi and Y. Ogihara, Phytochemistry, 19, 1878 (1980).

6- A. A. Ali, N. A. El-Emary and M. F. Darwish, Bull. Pharm. Sci., Assiut University, 16, 159 (1993).

7- A. Shawl, A. Vishwapaul and A. Kalla, Phytochemistry, 23, 2405 (1992).

8- F. Hanawa, S. Tahara and J. Mizutani, Phytochemistry, 30, 2197(1991).

9- A. Shawl, A. B. Dar and A.Vishwapaul, J. Nat. Prod., 48, 849 (1985).

10- F.-J. Marner and W. Hopper; Helvetica Chimica Acta, 75 (5), 197-198 (1993).

11- F. -J. Marner, A. N. B. Singab, M. M. AlAzizi, N. A. El-Emary and M. Schäfer, Phytochemistry, 60, 301, (2002). 
12- T. J. Mabry, K. R. Markham, and M. Thomas, The Systematic Identification of Flavonoids, Springer-Verlag, Berlin (1970).

13- World Health Organization, Bull. Wld. Hlth. Org., 33, 567-581 (1965).

14- J. T. Litchfield and F. W. Wilcoxon, J. of Pharmacol. and Exp. Thera., 96, 99-113 (1949).

15- J. C. Puchart and R. J. Campbell, The Aldrich Library of NMR Spectra, Aldrich Chemical Company, Milwaukee Wisconsin, USA, Vol. 4, 1974, p. 133.

16- J. B. Harborne (ed.), Phytochemical Methods of Analysis, Chapman and Hall, London (1973).

17- I. Smith, Chromatographic and Electrophoretic Techniques, $14^{\text {th }}$ edition, Heinemann, London (1976).
18- C. J. Yong, K. Kyoung, M. Seung, M. JaeHak and P.H.Keun, Food Sci.Biotechno., 9, 313 (2000).

19- M. A. M. Nawwar, A. S, Hussein, J. Bouddrus and M. Lincheid, Phytochemistry, 35, 1349 (1994).

20- S. Chien-Chang, C. Yuan-Shiun and H. LiKang, Phytochemistry, 34, 843 (1993).

21- A. E. Julian, G. Johnson, K. D. Johnson and J. B. Donnelly, Phytochemistry, 10, 3185 (1971).

22- A. R.Hilsenbeck, J. W Sharon, and T. J. Mabry, J. of Nat. Prod., 47 (2) Mar-Apr, 312-315 (1984).

23- A. A. Ali, N. A. El-Emary and F. M. Darwish, Bull. Pharm. Sci., Assiut University, 16, 159 (1993).

24- K. G. Mott, Plant Molluscicides. London, John Wiley and Sons (1987). 